\title{
Fault-Zone Waves Observed at the Southern Joshua Tree
}

\section{Earthquake Rupture Zone}

\author{
by S. E. Hough, Y. Ben-Zion, and P. Leary
}

\begin{abstract}
Waveform and spectral characteristics of several aftershocks of the M 6.122 April 1992 Joshua Tree earthquake recorded at stations just north of the Indio Hills in the Coachella Valley can be interpreted in terms of waves propagating within narrow, low-velocity, high-attenuation, vertical zones. Evidence for our interpretation consists of: (1) emergent $P$ arrivals prior to and opposite in polarity to the impulsive direct phase; these arrivals can be modeled as headwaves indicative of a transfault velocity contrast; (2) spectral peaks in the $S$ wave train that can be interpreted as internally reflected, low-velocity fault-zone wave energy; and (3) spatial selectivity of event-station pairs at which these data are observed, suggesting a long, narrow geologic structure. The observed waveforms are modeled using the analytical solution of Ben-Zion and Aki (1990) for a plane-parallel layered fault-zone structure. Synthetic waveform fits to the observed data indicate the presence of NS-trending vertical fault-zone layers characterized by a thickness of 50 to $100 \mathrm{~m}$, a velocity decrease of 10 to $15 \%$ relative to the surrounding rock, and a $P$-wave quality factor in the range 25 to 50 .
\end{abstract}

\section{Introduction}

The $M$ 6.1 Joshua Tree earthquake was followed by an energetic aftershock sequence. The very early aftershocks delineated the extent of the presumed mainshock rupture, approximately 10-km long (Nicholson and Hauksson, 1992). Later, the aftershocks spread to cover much of the area between the Pinto Mountain fault to the north and the Mission Creek fault to the south (Fig. 1a). Significant renewed aftershock activity occurred in this zone after the $M 7.428$ June 1992 Landers earthquake, delineating a NNW trend that merges into the previously defined major NS trend of the Joshua Tree aftershock zone (Sieh et al., 1993, Fig. 1b). The Joshua Tree-Landers earthquake sequence was characterized by a complex faulting process, covering many disjoint faultzone segments. Hough et al. (1993) showed that the southern post-Landers activity may be associated with an early large ( $M$ 5.7) aftershock of the Landers event. This large aftershock may have been responsible for $11 \mathrm{~km}$ of mapped surface rupture to the south of the Pinto Mountain fault (Rymer, 1992). Many questions remain about tectonic structure at the southern end of the Joshua Tree/Landers rupture, including the extent of the NS and NNW-trending faults and their interaction with the San Andreas fault.

In this article we use near-fault seismic observations of fault-zone head waves (FZHW's) and internal fault- zone reflections to infer high-resolution structure of small fault segments in the southern Joshua Tree region. We will also show that these fault segments can be plausibly considered to be extensions of newly identified fault segments in the southern Joshua Tree region. Crustal fault zones can generate seismic waveforms that are specific to their velocity structure, such as $P$ and $S$ headwaves propagating along faults that span a material contrast (BenZion and Aki, 1990; Ben-Zion and Malin, 1991). Another fault-specific diagnostic wave is due to seismic energy trapped in a low-velocity fault zone (Ben-Zion and Aki, 1990; Li and Leary, 1990; Leary and Ben-Zion, 1992). FZHW's arrive at near-fault stations before the direct body waves, and are characterized by an emergent waveform having reversed first-motion polarity from that of the direct arrival. Trapped wave energy arrives after the head, direct, and early scattered $S$ waves and can be observed as either a specific phase or a peak in the spectrum of the $S$ waveform. Fault-zone head and trapped waves are observed only if the event and the station are adjacent to the fault. If the event or the station are too far from the fault, the direct wave arrives first and obscures the headwave, while the trapped wave energy is attenuated away from the fault. In this work we analyze seismic fault-zone data recorded on portable instruments installed following the Joshua Tree earthquake. 


\section{Analysis}

\section{Observations}

Three days after the Joshua Tree earthquake, we deployed portable digital GEOS recorders with $\mathrm{L}-222 \mathrm{~Hz}$ sensors and force-balance accelerometers (fba's) at eight sites. The data are sampled at 200 samples/sec on all channels. Data from stations MCF, FVS, and GCA (Fig. 1) are used in this work.

Between 25 April and 11 June, 211 events were recorded by at least two of the eight GEOS sites. In the vicinity of stations FVS and MCF, there is no aftershock activity within about $3 \mathrm{~km}$ of the Mission Creek fault. In an effort to investigate the southernmost Joshua Tree region, we have focused our attention on the three southernmost aftershocks recorded by GEOS stations. The inset in Figure 1 shows two events on day 179, at 18:24 and 20:01 UTC (events 2 and 3, respectively), that occur below West Wide Canyon, and an event at 02:25 UTC on day 117 (event 1) below East Wide Canyon. Locations and magnitudes for events 1 and 2 are obtained from the USGS/Caltech Southern California Seismic
Network. Event 3 is not located by the network, but is assigned the same location as event 2 because of waveform similarity between the two events. The network magnitudes for events 1 and 2 are 2 and 1.5 , respectively. From the relative peak amplitudes of events 2 and 3, we estimate an approximate magnitude of 1 for event 3 .

Our initial interest in the southernmost aftershocks was to investigate the possibility that network locations contained systematic biases and that some of them might actually have occurred on the Mission Creek fault. However, observed $S-P$ times for the events confirm that they must be several kilometers north of the Mission Creek fault. On the other hand, we observed systematic waveform and spectral characteristics in the recordings of these events at certain stations, observations that are suggestive of fault-zone related phases.

The $P$-wave onsets for these events recorded on the NS component of station MCF are characterized by lowamplitude waveforms with reversed initial motion polarity from those of the closely following, large-amplitude, sharp secondary arrivals (Fig. 2). These features are indicative of fault-zone headwaves (e.g., Ben-Zion
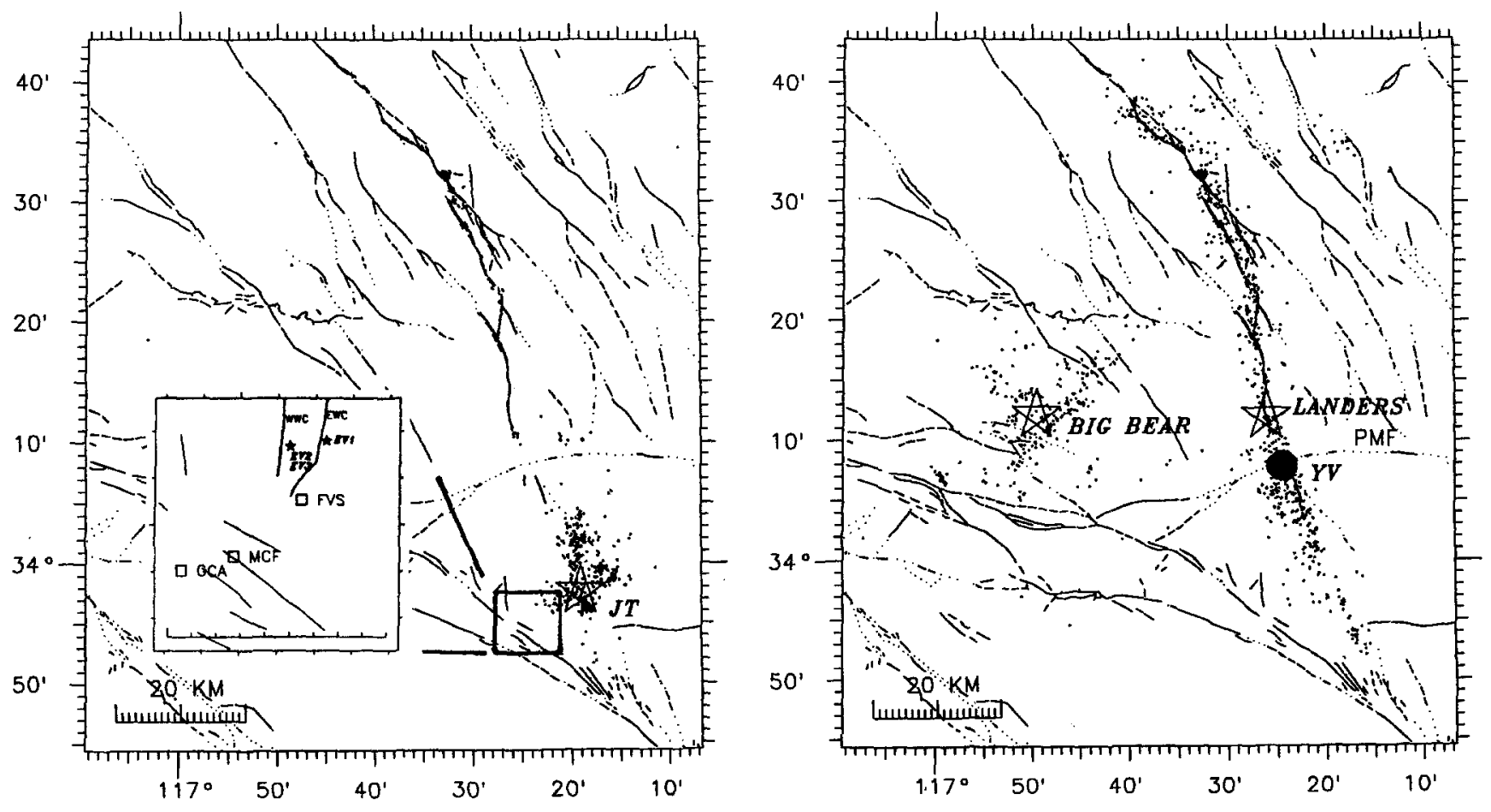

Figure 1. (a) A map of the southern Landers aftershock zone showing the locations of all $M>2.5$ aftershocks located through 27 June 1992 (dots), the Joshua Tree earthquake (JT; large star), and mapped surface rupture north and south of the Pinto Mountain fault. Inset shows detailed locations of stations FVS, MCF, and GCA; the axes of West and East Wide Canyons (WWC and EWC; dark lines); and the locations of events 1,2, and 3 (EV1,2, and 3; small stars). Event 3 is assigned the same location as event 2 based on their observed waveform similarity. (b) Similar to (a), but with all $M>3$ aftershocks for the period 28 June through 30 September 1992. The stars represent the locations of the Landers and Big Bear epicenters; the filled circle (YV) shows the location of an early M5.7 aftershock of the Landers event. 


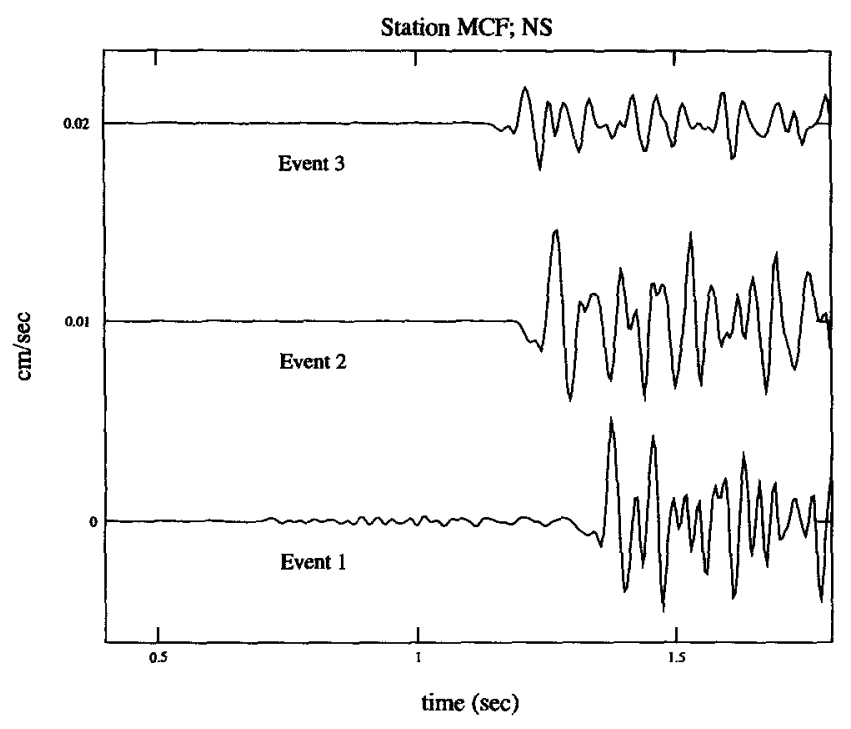

Figure 2. The onset of events 1 (bottom), 2 (middle), and 3 (top) on the NS component at station MCF. Time is arbitrary; the traces are shifted to show the onset. On all three records, the sharp (up) direct $P$ wave is preceded by an emergent (down) headwave arrival. For event 3 , a reverberatory precursor is observed. and Malin, 1991). Focal mechanisms cannot be computed for any of the events because sufficient first-motion data are not available. Event 1 also is recorded on stations FVS and GCA; however, the ambient noise is higher at these stations and its onset is obscured. The early oscillatory motion at the lower trace (event 1 ) may have resulted from a small precursory subevent which was arrested, but subsequently triggered a larger rupture elsewhere along the fault. Such space-time discontinuous ruptures are commonly simulated in the continuummechanics-based heterogeneous fault models of Ben-Zion and Rice (1994).

In addition to the early $P$-wave arrivals at station MCF, we also observed unusual spectral peaks in the shear waveforms of events 1,2 , and 3 recorded on NS components of the stations MCF and FVS. Figure 3 shows acceleration spectra corresponding to the three components of shear motion at station MCF for event 1; Figure 4 shows the NS spectrum from station FVS for the same event and the NS spectra at station MCF for events 2 and 3; and Figure 5 shows the NS spectrum from station GCA for event 1 and the NS component from station MCF for an event at $30-\mathrm{km}$ epicentral distance. We obtain acceleration spectra from the velocity data by multiplying the velocity spectra by angular frequency. In Figures 3 and 4 , we note for all events shear-wave spectral peaks near
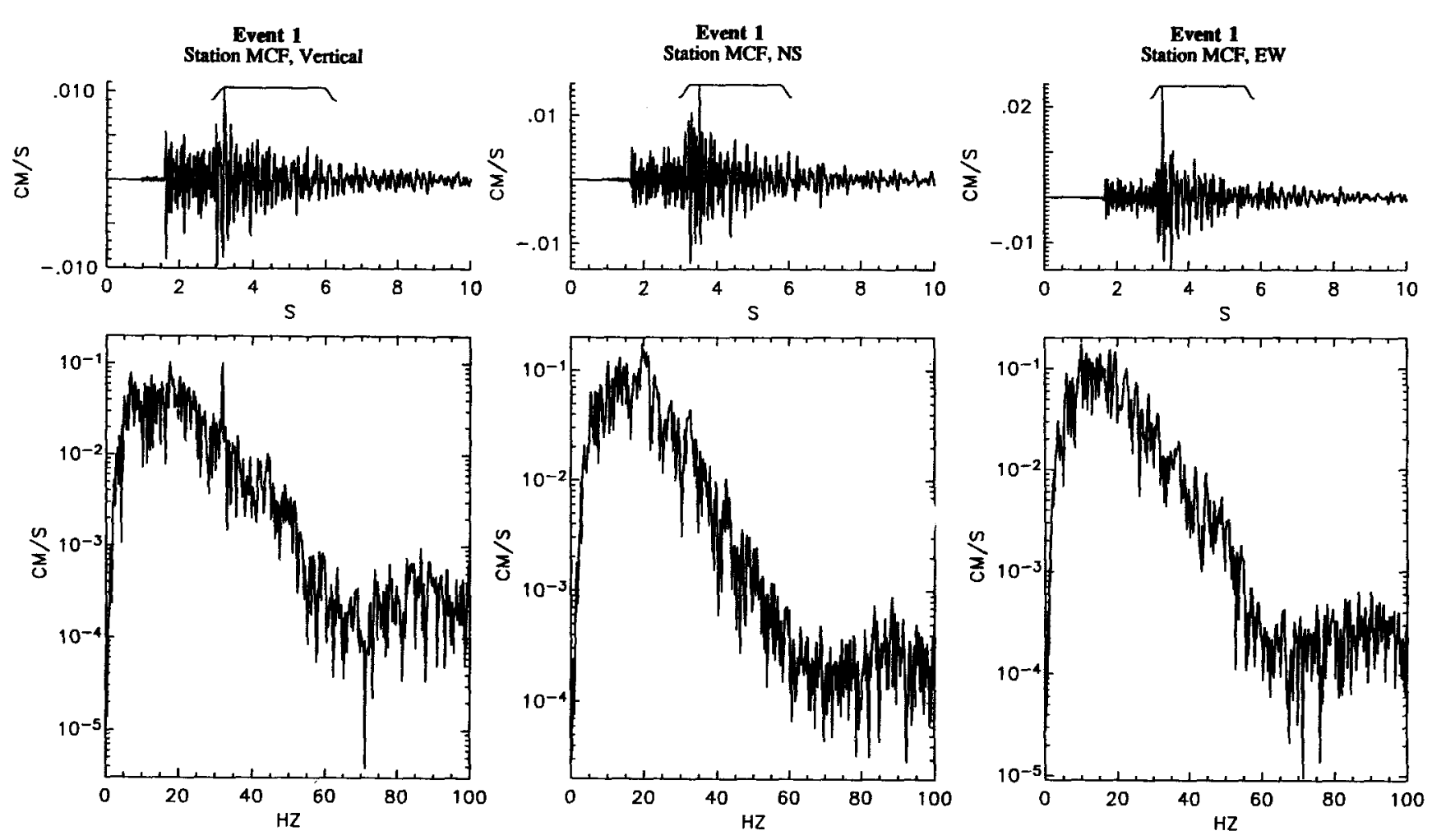

Figure 3. Shear-wave acceleration spectra for three components at station MCF for event 1 . The vertical, NS, and EW components are shown in the left, middle, and right panels, respectively. Time windows used to calculate spectra are indicated at top. 
20 to $25 \mathrm{~Hz}$ on the NS component at stations MCF and FVS. At station MCF, the spectral peaks are most pronounced for events 2 and 3. These peaks are absent on the EW and vertical components for the same event-station pairs (e.g., Fig. 3 for MCF); they also are not present on the NS components at FVS and MCF for more distant events (e.g., Fig. 5 for MCF), or in spectra from recordings at station GCA (Fig. 5). There is a suggestion of a higher-frequency (near $30 \mathrm{~Hz}$ ) peak in the verticalcomponent spectrum at MCF.

The spectra shown in Figures 3 through 5 are unsmoothed. While it is possible to reduce the variance of the spectral estimates with a smoothing operator, the resulting degradation in resolution is disadvantageous for the purposes of this study. Noting that the indicated spectral peaks are anomalous in comparison to other, similarly processed spectra from the same site (e.g., Fig. 5 ), we infer that they represent some resonance phenomenon.

Bonamassa and Vidale (1991) observed subtle directional site resonances at stations in the Santa Cruz Mountains following the 1989 Loma Prieta earthquake. This interpretation is implausible in our case because spectra from the NS component at the stations FVS and MCF from other, more distant events do not show similar peaks (e.g., Fig. 5).

Thus, although we are limited by the available data to observations from only three earthquakes, we observe unusual spectral and waveform characteristics in recordings of these events that cannot be attributed to either source or classical site effects. The spectral peaks correspond to enhanced high-frequency energy in the $S$ waves, an enhancement that is found to be visually apparent in subjective waveform comparisons. The larger data set, only one example of which is shown in Figure 5 , confirms the spatial selectivity of these characteristics and argues that their origin must lie with the specific event-receiver geometry. The observations are suggestive of seismic phases propagating within low-velocity fault-zone layers. Previous studies utilizing such waves (Li and Leary, 1990; Ben-Zion and Malin, 1991; Leary and Ben-Zion, 1992) have investigated seismic data recorded near fault zones whose existence was known $a$ priori. In the present work we observe possible faultzone waves that do not seem explicable in terms of known fault structure. In the next section we will show that the observations can be well modeled using existing theories of wave propagation within narrow fault zones oriented roughly NS, and will discuss the geologic implications of our seismological inferences.

\section{Modeling}

The data presented in Figures 2 through 4 are modeled here using the $2 \mathrm{D}$ analytical solution of Ben-Zion and Aki (1990) for scalar (i.e., acoustic $P$ or antiplane $S$ ) elastodynamic waves radiated from a laterally heter-
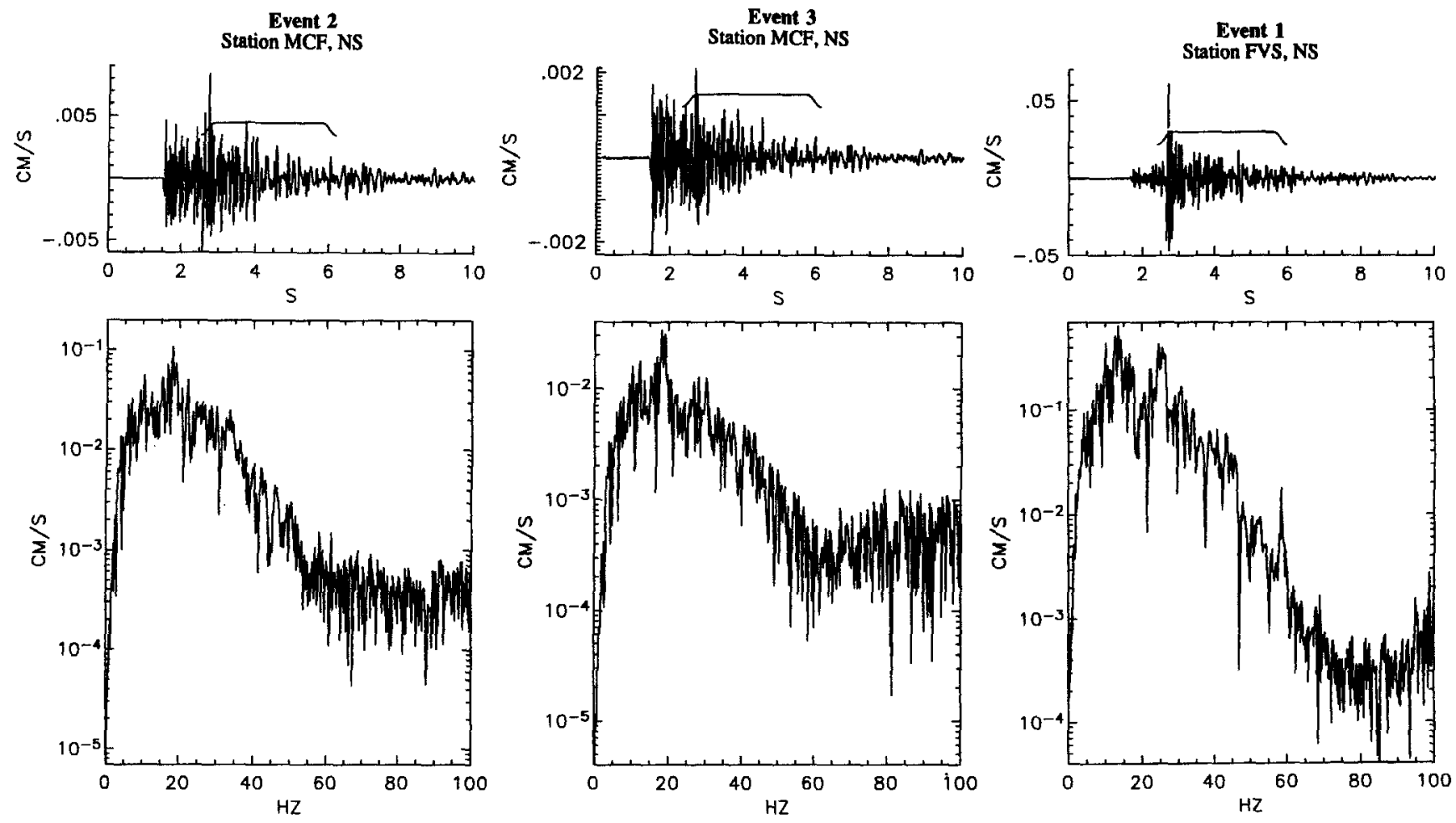

Figure 4. Shear-wave acceleration spectra from the NS component at station MCF for events 2 (left) and 3 (center), and from the NS component at station FVS for event 1 (right). 
ogeneous, plane-parallel, low-velocity fault-zone structure. When used in conjunction with $P$-wave velocities, the solution models near-fault $P$ waveforms in terms of $P$-to- $P$ fault-zone headwaves, direct $P$ waves, and multiply reflected $P$ waves propagating along the fault zone. When the solution is assigned typical $S$-wave velocities, it models near-fault shear waveforms in terms of $S$-to- $S$ FZHW's, direct $S$ body waves, and shear waves that are internally reflected in the fault-zone structure; for certain velocity structures and source-receiver configurations the latter waves produce large dispersive oscillations that are called fault-zone trapped waves. The generation and successful observation of fault-zone (head, internally reflected, and trapped) waves require that both source and receiver be close to the fault. The scalar elastodynamic model involves motions parallel to the fault-zone layers. Thus, for NS-trending faults the $P$ and $S$ fault-zone phases are expected to be predominantly observed on NS components of seismic records.

Figure 6 shows two synthetic $P$ waveform fits to the initial pulses of the data presented in Figure 2. The synthetic seismograms are calculated using a model con- sisting of two quarter spaces separated by a single vertical fault-zone layer. The quarter spaces are referred to as media 1 and 3; the fault-zone layer is medium 2 . The bottom frame in Figure 6 (model 1) corresponds to a source-receiver distance, $r=6 \mathrm{~km}$; a receiver offset from the fault, $x=325 \mathrm{~m}$; a fault-zone thickness, $w=85 \mathrm{~m}$; $P$-wave velocities, $\alpha 1=5.5 \mathrm{~km} / \mathrm{sec}, \alpha 2=5.0 \mathrm{~km} / \mathrm{sec}$ and $\alpha 3=5.25 \mathrm{~km} / \mathrm{sec}$; and $P$-wave quality factors, $Q 1$ $=Q 3=1000, Q 2=35$. A velocity contrast between the two quarter spaces is required for the generation of a headwave first arrival outside the fault zone proper. A further reduction of velocity (and quality factor) within the fault zone generates (attenuated) internal fault-zone reflections, and is required in order to obtain a good fit to the data. In calculating the synthetic seismogram of model 1, we use the real part of equation (5.88) of Aki and Richards (1980) to simulate material dispersion. The top frame (model 2) shows an alternative synthetic fit to the data, generated assuming $w=65 \mathrm{~m}, \alpha 2=4.75 \mathrm{~km} /$ sec, $Q 2=50$, and the other parameters of model 1. Here both the real and imaginary parts of equation (5.88) of Aki and Richards (1980) are employed to simulate ma-
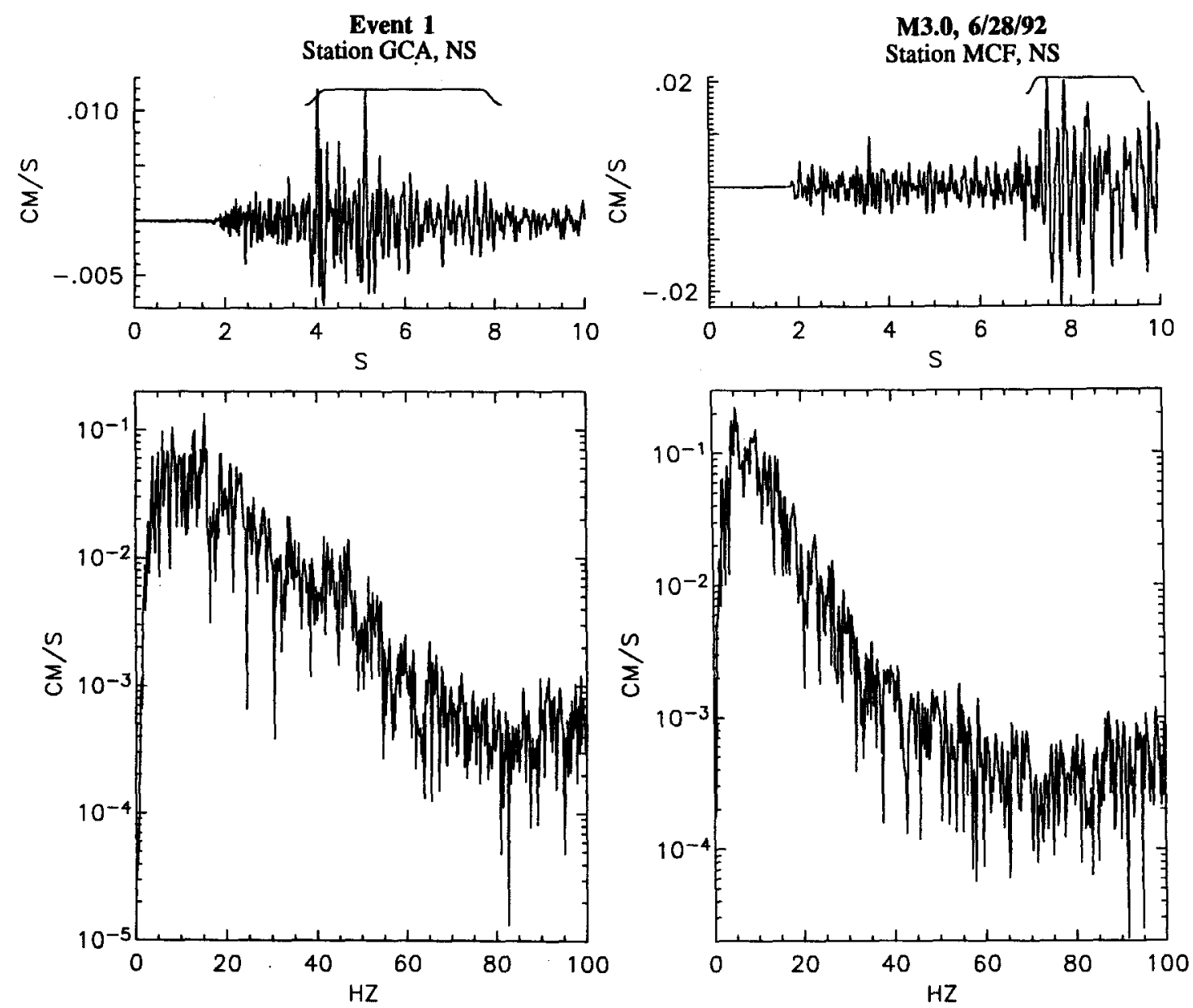

Figure 5. Shear-wave acceleration spectra for the NS component at station GCA for event 1 (left), and for the NS component at station MCF for a magnitude 3 foreshock of the Landers earthquake, at $30-\mathrm{km}$ epicentral distance. 
terial dispersion and intrinsic attenuation. For better comparison with the observed data, we show in Figure 7 the synthetic seismogram of model 2 together with the initial part of the top seismogram (event 3 ) of Figure 2. From Figures 6 and 7 it is seen that the model synthetic seismograms provide a good fit for the relative arrival times, amplitudes, and motion polarities of the first 3 to 4 oscillations in the observed near-fault data. We note that synthetic waveform calculations do not provide a unique structural interpretation, due to trade-offs between model parameters. A detailed study of such tradeoffs is beyond our scope and will be the subject of a separate work. For present purpose it is sufficient to say that an acceptable fit to the data, within the framework of the 2D solution (and within the limitations of our preferred interpretation), requires the existence of a 50 - to 100 -m-thick NS-trending fault zone having 10 to $15 \%$ velocity contrasts with the bounding crustal blocks and a $P$-wave quality factor on the order of 25 to 50 .

As mentioned above, the 2D solution of Ben-Zion
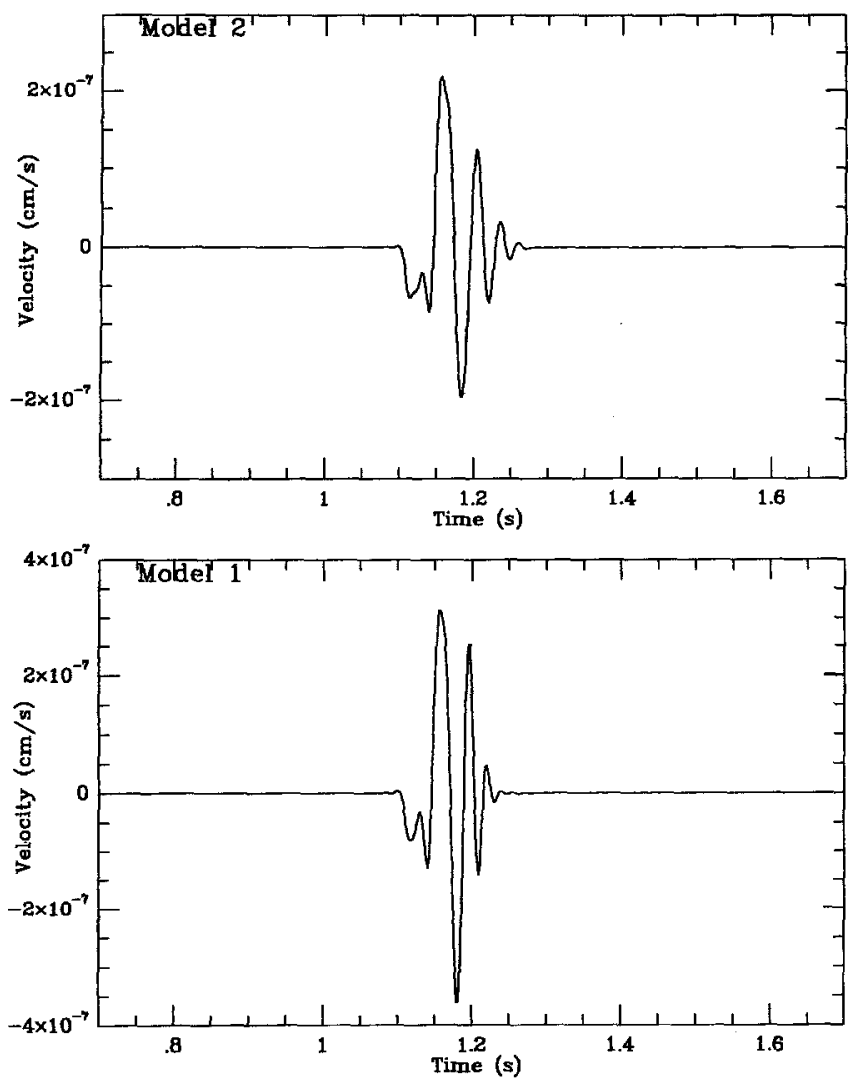

Figure 6. Near-fault synthetic $P$ waveform matching the data of Figure 2 for two different models. Motion is generated by a line dislocation source with a displacement discountinuity of $1 \mathrm{~cm}$. The source straddles the interface between the fast quarter space and the fault-zone layer, and is localized in space (Dirac delta function) and time (Heaviside unit step function). The assumed model parameters and source-receiver configuration are described in the text. and Aki (1990) can be understood in terms of both acoustic $P$ and antiplane $S$ waves. To obtain from the synthetic seismograms of Figure 6 corresponding near-fault shear waveforms, one needs only to stretch (multiply) the time axes by the velocity ratio of the $P$ and $S$ waves; for a Poisson solid this ratio is $\sqrt{3}$. Thus, the synthetic seismograms of Figure 6 predict a spectral peak around 20 $\mathrm{Hz}$ in the shear waveforms of the observed seismograms shown in Figure 2. As noted, the spectral peak at station MCF from event 1, occurring below the East Wide Canyon, is less pronounced than those present for events 2 and 3 on the West Wide Canyon. This is consistent with the interpretation that the peaks represent internal faultzone reflections, because station MCF is closer to the extrapolated trend of the inferred fault (Fig. 1).

\section{Discussion}

Our study suggests that moderate to well-developed low-velocity fault zones may exist between the analyzed events and recording stations MCF and FVS. Our interpretation of the data is not unique, and it is possible to provide alternative explanations for partial sets of the observations. For example, headwaves can be generated

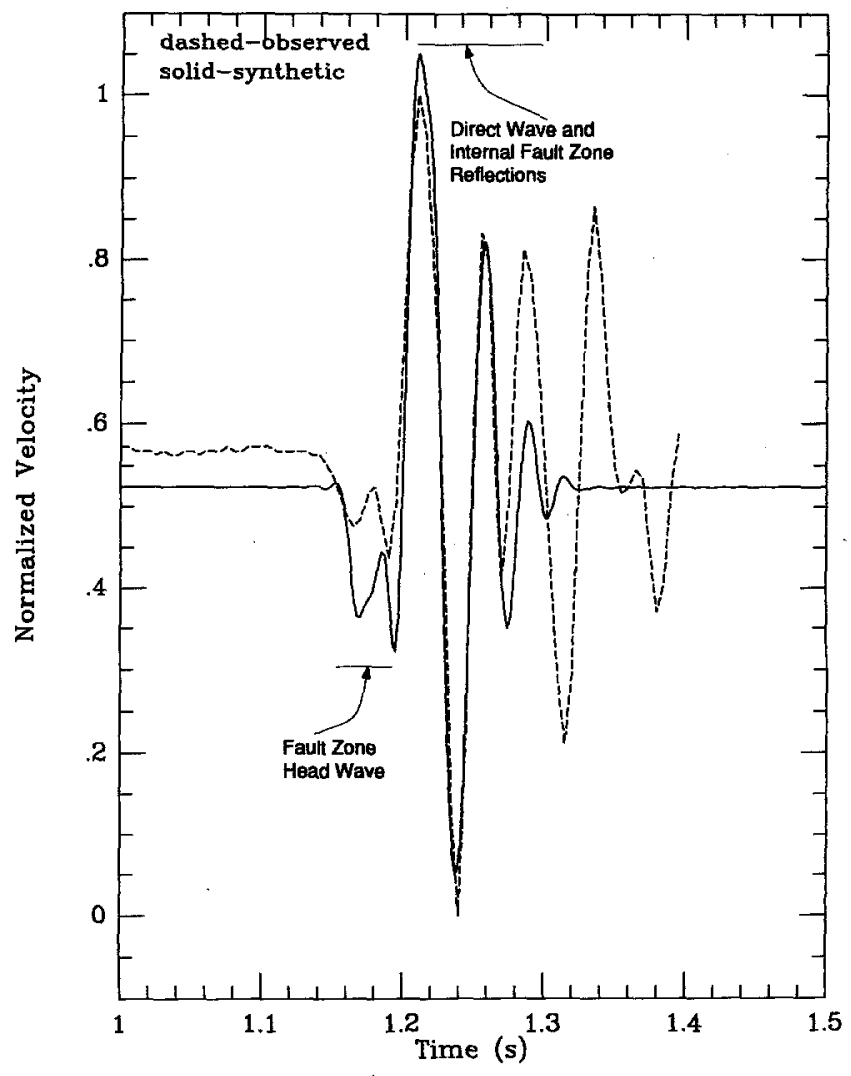

Figure 7. Synthetic seismogram (solid line) and initial part of observed data (dashed line). The synthetic data is generated by model 2 (top frame) of Figure 6 . The observed data was recorded during event 3 (top trace) of Figure 2. 
along a velocity contrast with any orientation, including horizontal. Those, however, will not have the near-fault spatial selectivity of event-station pairs observed in our data. Alternative explanations for the spectral observations are not obvious; explanations that evoke unusual source properties or directional site effects have been ruled out. Although the data set available for analysis is limited, it provides definite observations of anomalous spectral and waveform characteristics for which even an obvious qualitative explanation is lacking. The interpretation of the analyzed data in terms of fault-zone waves provides a simple and coherent explanation for the emergent, opposite motion polarity, early $P$-wave arrivals, the polarized $S$ spectral peaks, and the spatial selectivity of event-station pairs.

The analyzed events are located immediately below the East and West Wide Canyons, at the southern edge of the Little San Bernadino Mountains. These are two in a series of subparallel canyons which extend northward from the base of the mountains. Several kilometers to the east is West Deception Canyon (WDC), which is underlain by a fault that is inferred to have been responsible for the Joshua Tree mainshock (Rymer, 1992). Faults have also been mapped along both the East Wide Canyon (EWC) and the Long Canyon (farther east from WDC); the surface expression of the EWC fault is consistent with our interpretation that the fault zone is well developed (Rymer, personal comm.).

Our observations and modeling suggest the presence of faults that continue from EWC and West Wide Canyon (WWC) to intersect the Mission Creek fault north of the Indio Hills. It is not clear if the observed first-motion polarities are consistent with right-lateral motion along these faults; however, focal mechanisms within aftershock sequences are known to be very complex (e.g., Beroza and Zoback, 1993).

Rymer (1993) concludes that slip transfer from the San Andreas fault to the northerly trending WDC and EWC faults occurs via short NW-trending faults that "horsetail" off of the San Andreas fault (SAF). It is thus possible that our inferred southern extensions of faults under EWC and WWC represent preexisting fault structures that are not active in the current tectonic regime.

The usefulness of fault zone waves in elucidating properties of fault zones has been well documented (e.g., $\mathrm{Li}$ and Leary, 1990; Ben-Zion and Malin, 1991; Leary and Ben-Zion, 1992). We suggest that the usefulness of these waves may transcend investigation of known fault zones. Although our suggestions remain speculative, we have presented what is, as far as we know, the first use of fault zone waves to infer the existence of faults and fault extensions that could not have been distinguished based on their recent seismicity. We are also able to investigate the physical properties of these inferred faults. An accurate determination of fault-zone properties (e.g., width and velocity) has first-order importance for correct derivation of earthquake parameters (e.g., locations and focal mechanisms) and mechanical simulations of crustal responses (e.g., stress redistribution after an earthquake and postseismic fault slip). We suggest that the observation and modeling of fault-zone waves provide an important tool for high-resolution mapping of fault-zone properties, and perhaps for the identification of previously unrecognized fault zones as well.

\section{Acknowledgments}

We gratefully acknowledge the cooperation and patience of the homeowners who allowed us to deploy instruments on their property. We thank E. Sembera, C. Mueller, G. Glassmoyer, L. Wennerberg, and $\mathrm{S}$. Lydeen for their efforts in instrument deployment, maintenance, and data processing. We thank Jim Mori, Tom Heaton, and an anonymous reviewer for reviews of the manuscript, and $\mathbf{M}$. Rymer for his review and helpful discussions.

\section{References}

Aki, K. and P. G. Richards (1980). Quantitative Seismology, W. H. Freeman and Co., San Francisco.

Ben-Zion, Y. and K. Aki (1990). Seismic radiation from an SH line source in a laterally heterogeneous planar fault zone, Bull. Seism. Soc. Am. 80, 971-994.

Ben-Zion, Y. and P. Malin (1991). San Andreas fault zone head waves near Parkfield, California, Science 251, 1592-1594.

Ben-Zion, Y. and J. R. Rice (1994). Slip patterns and earthquake populations along different classes of faults in elastic solids, $J$. Geophys. Res. (submitted for publication).

Beroza, G. and M. Zoback (1993). Mechanism diversity of the Loma Prieta aftershocks and the mechanics of mainshock-aftershock interaction, Science 259, 210-213.

Bonamassa, O. and J. E. Vidale (1991). Directional site resonances observed from aftershocks of the 18 October 1989 Loma Prieta earthquake, Bull. Seism. Soc. Am. 81, 1945-1957.

Hough, S. E., J. Mori, E. Sembera, G. Glassmoyer, C. Mueller, and S. Lydeen (1993). Surface rupture associated with the $6 / 28 / 92$ M 7.4 Landers earthquake: did it all happen during the mainshock? Geophys. Res. Lett. 20, 2615-2618.

Leary, P. and Y. Ben-Zion (1992). A $200 \mathrm{~m}$ wide fault zone low velocity layer on the San Andreas fault at Parkfield: results from analytic waveform fits to trapped wave groups, Seism. Res. Lett. 63, no. $1,62$.

Li, Y. G. and P. Leary (1990). Fault zone seismic trapped waves, Bull. Seism. Soc. Am. 80, 1245-1271.

Nicholson, C. and E. Hauksson (1992). The April 1992 ML 6.1 Joshua Tree earthquake sequence: seismotectonic analysis and interpretation (abstract), EOS 73, 363.

Rymer, M. (1992). The 1992 Joshua Tree, California, earthquake: tectonic setting and triggered slip, EOS 73, 363.

Sieh, K., L. Jones, E. Hauksson, K. Hudnut, D. Eberhart-Phillips, T. Heaton, S. Hough, K. Hutton, H. Kanamori, A. Lilje, S. Lindvall, S. F. McGill, J. Mori, C. Rubin, J. A. Spotila, J. Stock, H. K. Thio, J. Treiman, B. Wernicke, and J. Zachariasen (1993). Near-field investigations of the Landers earthquake sequence, April to July, 1992, Science 260, 171-176.
U.S. Geological Survey

Pasadena, California 91106

(S.E.H.)

University of Edinburgh

Edinburgh, Scotland

(P.L.)
Harvard University

Cambridge, Massachusetts 02138 (Y.B.-Z.)
Manuscript received 18 August 1993. 